\title{
Fuzzy Logic and Their application in Different Areas of Engineering Science and Research : A Survey
}

\author{
Dr. Amit Kumar Gupta \\ Assistant Professor, Department of Mathematics, Gangasheel Mahavidhyalaya, Nawabganj Bareilly \\ (Affiliated to M.J.P Rohilkhand University, Bareilly, Uttar Pradesh, India)
}

\begin{abstract}
Article Info

Volume 8, Issue 2

Page Number : 71-75

Publication Issue

March-April-2021

\section{Article History}

Accepted : 02 March 2021

This Paper give introduction to Fuzzy Logic and Various application in different branch of Engineering and Research. Fuzzy Logic is Applied branch of Mathematics in which Lots of research is taking place. Fuzzy Logic works on "if.....then....." Fuzzy Logic gives the idea that members are not restricted to $\mathrm{T}$ or F definition. The concept of Fuzzy Logic is used in the various fields as Artificial Intelligence, Aerospace, Automotive Business, Defence, Electronics, Finance, Industrial Sector, Marine Sector, Manufacturing, Medical, Securities, Transportation Pattern Recognition and Classification, Psychology, etc. The whole field of Engineering as civil Engineering, Mechanical Engineering, Industrial Engineering real Reliability theory, Robotics, Computer Engineering is broad to be covered here in a comprehensive way.
\end{abstract}

Published : 09 March 2021
Keywords : Application of Fuzzy system, Fuzzy Logic rule, Fuzzy theory Survey

\section{INTRODUCTION}

Fuzzy Logic was First Proposed by Lotfi Zadeh of the University of California at Berkeley, United State in 1965. it has observed that Conventional Computer Logic could not manipulate due to that represented Subjective over vogue ideas, So he created Fuzzy Logic to allow Computer to determine the distinctions among do data with Shades of gray. Similar to the Process of human thinking. The word Fuzzy refers to things which are not clear are vogue. Any event Process or Function that is Changing Continuously can not always be defined as either True or False. Fuzzy
Logic resembles the human decision-making methodology. It deals with vogue and imprecise information. This is a gross over simplification of real word problems and based on degree of truth rather than usual True/False or 1/0 like Boolean logic the following diagram shows that in a Fuzzy systems, the values are indicated by a numbers in the range from 0 to 1 . Here 1.0 represent absolute True and 0.0 represents Absolute Falseness. The number which indicates the value in Fuzzy system is called the truth value. 


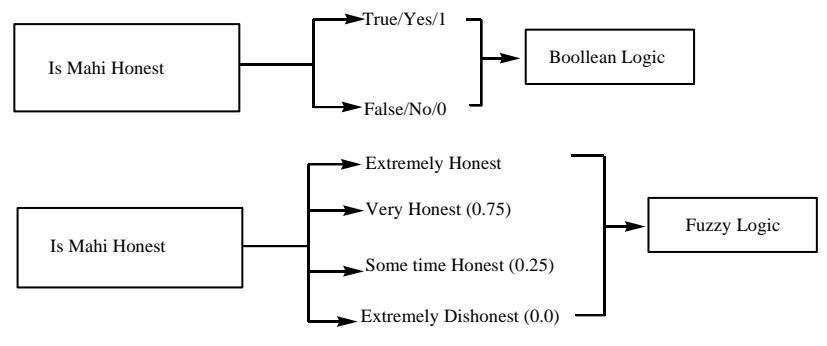

Fuzzy sets can be considered as an Extension and gross over simplification of classical sets. It can be understood in the context of set membership. Basically it allows partial membership which means that it contain elements that have varying degrees of membership in the set. Classical sets contains element does that satisfies precise properties of membership while Fuzzy set contains elements that satisfy imprecise properties of membership. Membership function characterized Fuzziness whether the elements in Fuzzy sets are discrete or continuous. Membership function are represent represented by graphical forms.

\section{Fuzzy Logic rule Base}

The representation of human knowledge can be done with the help of following natural Language expression

IF antecedent THEN consequent

The above expression is referred to as the Fuzzy "if....then" rule base.

The canonical form of Fuzzy Logic rule baseRule 1- If condition $\mathrm{P}_{1}$, then restrictions $\mathrm{Q}_{1}$. Rule 2- If condition $\mathrm{P}_{1}$, then restrictions $\mathrm{Q}_{2}$

Rule n-If condition $\mathrm{P}_{1}$, then restrictions $\mathrm{Q}_{\mathrm{n}}$.

Fuzzy if Then "Rules can be interpreted in the following four terms,

i. Assignment statement:- These kinds of statement use "=" sign for the purpose of assignment.

$$
\begin{aligned}
\text { Climate } & =\text { Rain } \\
\text { Hungry } & =\text { Food } \\
\text { Life } & =\text { Oxygen }
\end{aligned}
$$

ii. Condition Statements:- These Kind of statements use the "IF.....THEN" rule base form for the purpose of condition. They are the following form

"If temperature is Low THEN climate is cold"

iii. Unconditional statements:- These type of statements are of following form

\section{"Turn the Fan OFF"}

iv. Linguistic variable:- Fuzzy Logic is uses Linguistic variables which are very hot or cold, slightly cold, very warm, slightly warm, etc. Here is the words very, slightly, etc, are the Linguistic.
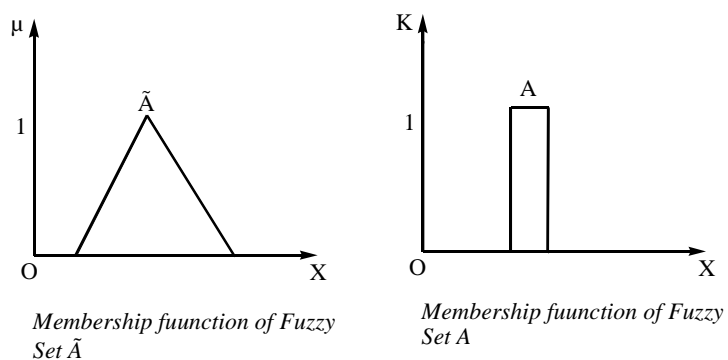

A Fuzzy Set $\tilde{A}$ in the Universe of the information $\mathrm{U}$ can be defined as a set of ordered Pair and it can be represented as

$$
\tilde{A}=\{(x, \mu \tilde{A}(x)) \quad x \in U\} \quad \forall \quad \mu \tilde{A}(x)=\text { degree } \quad \text { of }
$$
membership of $x$ in/widetilde $\{A\}$, assume values in the range from 0 to 1 i.e $\mu \tilde{A}(x) \in[0,1]$

Now consider two cases of universe of information as,

1. When universe of information $U$ is discrete and finite then $\tilde{A}=\sum_{i=1}^{n} \frac{\mu_{\tilde{\Lambda}}\left(\mathrm{x}_{\mathrm{i}}\right)}{\mathrm{x}_{\mathrm{i}}} \forall \sum$ represent the collection of each element.

2. When universe of information $U$ is continuous and finite than $\tilde{A}=\int \frac{\mu_{\tilde{A}}(x)}{x}$ for any Fuzzy Set $\tilde{A}$, the boundary of a membership function is the region of the 
universe that is characterized by a non zero bit in complete membership in the set. Hence core consist of all those elements $\mathrm{x}$ of the inverse of information such that

$1>\mu \tilde{\mathrm{A}}(\mathrm{x})>0$

2>

Reducing a fuzzy set into a crisp set in known as

Defuzzification.

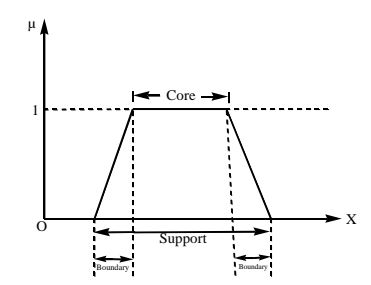

Algorithm of Fuzzy decision is

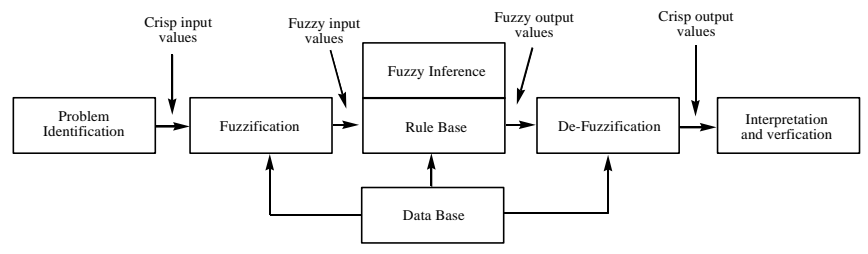

II. APPLICATION

In this research paper we discuss the various fields where the concept of fuzzy logic are applied as follows,

A. Psychology:- In psychology, the Fuzzy Logic is used in following areas,

- Analysis of human behavior

- Criminal investigation and prevention

B. Transportation:- In transportation Fuzzy Logic is used in following areas,

- Automatic underground train operation

- Breaking and stopping

- Train schedule control

- Railways acceleration

C. Medical:- In medical field, Fuzzy Logic is used in following areas,

- Medical diagnostic support system

- Radiology diagnosis
- Multivariable control of anesthesia

- Modeling of neuro pathological finding in Alzheimer's patients

- Fuzzy inference diagnosis of diabetes and prostrate cancer

D. Securities:- In securities, Fuzzy logic is used in following areas,

- Decision system for securities trading

- Securities appliances

E.Marine:- In the marine field, Fuzzy logic is used in the following areas,

- Autopilot of ships

- Optimal root selection

- Control of autonomous under water vehicles

- Ship steering

F. Finance:- In finance field, Fuzzy Logic is used in following areas,

- Bank note transfer control

- Find management

- Stock market prediction

G. Electronics:- In electronics Fuzzy Logic is used in following areas,

- Control of automatic exposure in video cameras

- Humidity in a clean room

- Air conditioning system

- Washing machine timing

- Microwave, ovens, vacuum cleaners, etc.

H. Defense:- In defense Fuzzy Logic is used in following areas,

- Underwater target recognition

- Automatic target recognition of thermal infrared images

- Naval decision support aids

- Control of a hypervelocity interceptor

- Fuzzy set modeling of NATO decision making

I. Automotive:- In automotive Fuzzy Logic is used in following areas,

- Intelligent Highways systems

- Traffic control 
- Improving efficiency of automotive transmissions

- Shift scheduling method for automotive transmissions

- Trainable Fuzzy system for speed control

\section{RESEARCH DIRECTION}

In this include the different domain engineering science and research where the Fuzzy Logic can we helpful for improving the existing models. During the survey of different article and research paper, it is recognised the Fuzzy logic is one of the most essential technique for processing data and obtain the fruitful pattern.

\subsection{Fuzzy mathematical approach for selecting candidate for election by a political party}

A team of observed from a party will like to select a candidate who are willing to contest the election then following steps can be followed and weighted mean to be calculate.

- Fixing the parameters which can be used to select a candidate

- Assigning the gradation of these parameter

- Formation of observer's entry shift

- Devising method to calculate index of goodness of each candidate according to each observer

- Calculations which will lead to selection of proper candidate who will fight election on behalf of the party

\subsection{IOT enabled smart monitoring of Coronavirus} empowered with Fuzzy inference system

IOTSMCFIS system is used to resolve the need for smart FIS coronavirus monitoring which consists of two cloud-connected phase, the first is a training phase and second is a validation phase.
The training phase comprises three level: sensory layers, pre-processing and application layer. Sensory comprise input parameter: flu, headache, sore throat and fever that accumulate and transfer the input values therefore called raw data. The processing layer in the next and very critical layer, the missing values are controlled by moving average and normalisation in order to reduce noisy results. The data is forward to the application layer after pre processing. The application layer is divided into two layer: prediction and perform layer. FIS is used in the prediction layer to predict the output. The input has been grouped and altered to a Fuzzy set with Fuzzy linguistic variables, semantic terms, Fuzzy membership function. During the following point, Fuzzy modification will be made by FIS. FIS is the way to suppose to give source input by using Fuzzy logic, after which Fuzzy set possibilities are transformed into a Fuzzy Set in defuzzifier. FIS is used to predict the coronavirus in prediction layer. If sensory input parameter are appropriate, it will move via a Fuzzfiction into the Fuzzy crisp inputs. The crisp set of input data is obtained and transformed into Fuzzy using Fuzzy linguistic variable. Fuzzy sematic terms and membership function.

\subsection{Applications of Fuzzy Logic in chemical process}

Fuzzy Logic in chemical process are used in following steps,

- Piping risk assessment

- Furnace control

- Modelling of the fluidised catalytic cracking unit of a petrochemical refinery

- Separation processes

- PH controllers

- Combustion processes 


\subsection{Application of Fuzzy Logic in image processing}

Fuzzy Logic used in image processing as in following steps,

- Mapping of image into the Fuzzy domain

- Operation in the Fuzzy Domain

- Defuzzification function The several Fuzzy images processing applications are described to

- Fuzzy binarization

- Fuzzy edge definition

- Fuzzy geometry measurement

Fuzzy image processing is the collection of all approaches that understand, present and process the image, their segments and features as Fuzzy set. Fuzzy image processing has three main stages:

- Image Fuzzyfiction

- Modification of membership values

- Image defuzzification

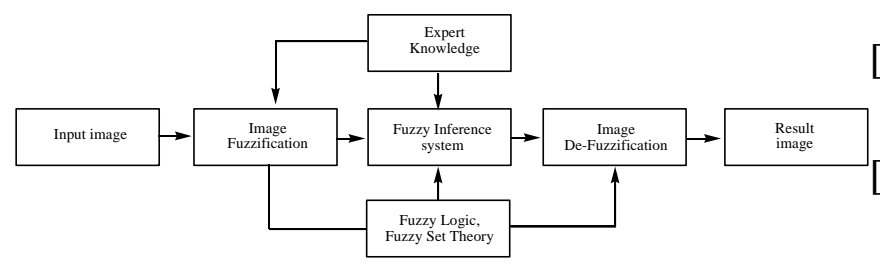

\section{REFERENCES}

[1]. Role of fuzzy Logic in decision making process (Thomas Klicstik), University of Zilina

[2]. Artificial intelligence by Elain Rich, Kelvin Knight and Schivashnakar B. Nair

[3]. Websites

[4]. https://www.tutorialpoint.com/fuzzy-logicapplicaton.htm

[5]. https://www.researchgate.net/figure/Algorit hm-of-Fuzzy-decsion

[6]. https://www.guru.99.com/what-is-fuzzylogic.htm $1 \neq 3$

[7]. Timothy J. Ross, "Fuzzy Logic with Engineering application", John Wiley and sons Ltd.

[8]. International journal of advance research, ideas and innovations in Technology, Volume, Issum I, ISSN : 2554-132X

[9]. Rajeev G.Sapre and Ms. Snehal Kalambata, "international journal of Fuzzy mathematics and system", volume 2, number3 (2012)

[10]. Mario I.Chacon M. "Fuzzy logic for image processing"

[11]. Dr. C. SugaPriya, "Quality improvement of image processing using fuzzy logic system".

\section{Cite this Article}

\section{IV.CONCLUSION}

Fuzzy logic provides way to calculate with imprecision and vagueness. Fuzzy Logic can be used to represents some kind of human expertise. The control stability, reliability, efficincy and durability of Fuzzy Logic makes it popular. The speed and complexity of application production would not be possible without system like Fuzzy Logic.
Dr. Amit Kumar Gupta, "Fuzzy Logic and Their application in Different Areas of Engineering Science and Research : A Survey", International Journal of Scientific Research in Science and Technology (IJSRST), Online ISSN : 2395-602X, Print ISSN : 2395-6011, Volume 8 Issue 2, pp. 7175, March-April 2021. Available at doi : https://doi.org/10.32628/IJSRST218212

Crited-bsy
Cref

Journal URL : https://ijsrst.com/IJSRST218212 